\title{
Effect of Pro Oxidant Agents on the Ageing of Polypropylene
}

\author{
Fatima Bensaad ${ }^{a}$ and Naima Belhaneche-Bensemra *,b \\ ${ }^{a}$ Laboratory of Materials Coating and Environment, University M'Hamed Bougara, Boumerdes, Algeria \\ ${ }^{b}$ Laboratory of Sciences and Techniques' of Environment, National Polytechnic School, Algiers, Algeria
}

\begin{abstract}
The aim of this work is to study the influence of pro oxidant agents on the natural ageing of polypropylene (PP). For that purpose, two formulations containing, respectively, $5 \mathrm{wt} \%$ of $\mathrm{Ca}$ stearate and $\mathrm{Ca} / \mathrm{Zn}$ complex as pro oxidant agents were prepared and exposed during 18 months to exterior natural conditions of Mediterranean climate. For comparison, a control formulation based only on PP was prepared.

Samples were taken off every three months and characterized. The evolution of mechanical properties was followed by tensile test and Shore D hardness while the chemical modifications were analysed by Fourier transform infrared spectroscopy (FTIR).

The results showed that all the considered formulations were affected but those containing the pro oxidant agents were the most affected.

Moreover, Ca stearate is more effective than $\mathrm{Ca} / \mathrm{Zn}$ complex as pro oxidant agent.
\end{abstract}

Keywords: Polypropylene, Natural Ageing, Pro Oxidant Agent, Photodegradation.

\section{Introduction}

The thermoplastic packaging is a product of everyday use. Its multiplicity allows it to be present in all industrial sectors: agriculture and food chain, cosmetics, health, maintenance products, chemicals, transport, distribution, industrial and agricultural products. During these last years, the thermoplastic packaging has expanded considerably. These materials have the advantage to be cheap, light, resistant and easy to put in use.

The polypropylene (PP) is a large diffusion thermoplastic. Its production represents more than the fifth of the total production of the plastic materials. Its exceptional development in the last decades is due to a constant improvement of industrial manufacturing processes, to the possibility to vary in a large scale its properties by copolymerising it in different ways and by adding to it loads and reinforcement. The polypropylene is used in almost all fields and in particular in the agricultural sector and in packaging [1].

However, as this material is not biodegradable and the quantity that is produced is in its majority not recyclable, the

${ }^{*}$ Corresponding author

E-mail: nbelhaneche@yahoo.fr

(C) 2015 International Association for Sharing Knowledge and Sustainability

DOI: $10.5383 /$ swes.7.02.001 waste of the packaging tends to accumulate in the environment and to generate visual pollution. Incorporating bio oxidizing agents in order to accelerate the deterioration of the polypropylene and to make the products of deterioration more sensitive to biodegradation is a promising solution to the problem of environment protection. These agents are transitive metallic ions such as $\mathrm{Fe}$ or $\mathrm{Mn}$, when added to polymers under the form of stearates or organic complexes; they can increase the rate of oxidation in presence of the oxygen of the air and the cleavage of the polymeric chains under the influence of temperature and / or light $[2,3]$.

The aim of this work is to study the influence of $\mathrm{Ca}$ stearate and $\mathrm{Ca} / \mathrm{Zn}$ complex as pro oxidant agents for $\mathrm{PP}$.

\section{Experimental}

\subsection{Materials}

The used PP is a homopolymer grade injection (SABIC, Saudi Arabia). The pro oxidizing agents are Ca stearate (PROLABO, France) and $\mathrm{Ca} / \mathrm{Zn}$ complex (BETAQUIMICA, Spain). 


\subsection{Films Preparation}

A mono screw extruder was used to prepare three formulations: F-1 containing PP (control), F-2 and F-3 containing, respectively, 5\% of $\mathrm{Ca}$ stearate and $\mathrm{Ca} / \mathrm{Zn}$ complex. Tube dumbbells $(150 \mathrm{~mm} \times 10 \mathrm{~mm} \times 4 \mathrm{~mm})$ were obtained according to the standard NF EN 1SO 527.

\subsection{Natural Ageing}

The three formulations were exposed during 18 months to natural conditions in a Mediterranean climate according to the standard NF EN ISO 877. Samples were taken off every three months to be characterized.

\subsection{Samples Characterization}

\subsubsection{Fourier Transform Infrared Spectroscopy (FTIR)}

The analysis was carried out by using a FTIR spectrophotometer brand Perkin Elmer instrument with a resolution of $4 \mathrm{~cm}-1$ and a number of scans of 32 .

\subsubsection{Tensile Test}

The tensile test was carried out using a machine brand ZWICK, type BTC-FR2, 5TN.D09 piloted by a computer with software Test Xpert V10.11 according to the standard NF EN ISO 527 at a crosshead speed of $100 \mathrm{~mm} / \mathrm{mn}$. The results were obtained by averaging the values of five measurements.

\subsubsection{Shore D Hardness}

The hardness was measured using a hardness meter type Shore D according to the standard ISO 291. The value of the hardness is the average obtained in five different points of the same sample.

\section{Results and Discussion}

\subsection{Visual Observations}

During the natural ageing, the studied formulations exhibited the following modifications:

- All formulations turned yellow;

- Appearance of cracklings;

- Chalking of samples that contain pro oxidants and formation of a coat of oxygenated products after three months of ageing, the thickness of this coat increased with time;

- Weakening of all the formulations during the natural ageing.
Table.1 Evolution of Shore D Hardness with Time of Ageing

\begin{tabular}{|c|c|c|c|}
\cline { 2 - 4 } \multicolumn{1}{c|}{} & \multicolumn{3}{c|}{ Shore D hardness } \\
\hline $\begin{array}{c}\text { Time } \\
\text { (months) }\end{array}$ & F1 & F2 & F3 \\
\hline 0 & $73 \pm 0.60$ & $72 \pm 0.52$ & $72 \pm 0.30$ \\
\hline 3 & $70 \pm 0.53$ & $71 \pm 0.73$ & $72 \pm 0.00$ \\
\hline 6 & $66 \pm 0.15$ & $64 \pm 0.00$ & $66 \pm 0.10$ \\
\hline 9 & $64 \pm 0.73$ & $63 \pm 0.00$ & $64 \pm 0.00$ \\
\hline 12 & $64 \pm 0.51$ & $61 \pm 0.57$ & $63 \pm 0.15$ \\
\hline 15 & $63 \pm 0.00$ & $56 \pm 0.00$ & $61 \pm 0.57$ \\
\hline 18 & $58 \pm 2.60$ & $42 \pm 0.70$ & $53 \pm 0.73$ \\
\hline
\end{tabular}

\subsection{Evolution of Mechanical Properties}

Figures 1 and 2 show, respectively, the evolution of elongation and stress at break of the three formulations with time of natural ageing while Table 1 shows the evolution of Shore D hardness with time of natural ageing. It can be noted that the initial values of elongation at break, tensile at break and Shore $\mathrm{D}$ hardness of the three formulations before the ageing are practically similar which indicates that the pro oxidant agents have no influence during the processing of the formulations. These results are in agreement with another similar study [4]. A considerable decrease of elongation at break was observed after three months of ageing for the three formulations which indicates the sensitiveness of PP to solar radiations. On the other hand, tensile at break and Shore D hardness decreased continuously since the first months of exposure. The decrease of the mechanical properties is due to the chains scissions that occurred during the photo oxidation [5].

The most noticeable decrease of mechanical properties occurred in the case of formulation F2 which contains Ca stearate as pro oxidant agent. This indicates that $\mathrm{Ca}$ stearate has better efficiency as pro oxidant agent than the $\mathrm{Ca} / \mathrm{Zn}$ complex.

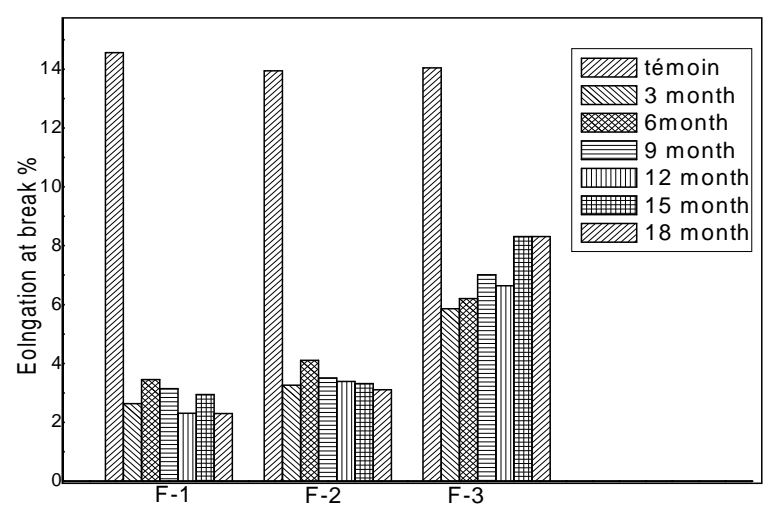

Fig.1 Evolution of Elongation at Break with Control of Ageing 


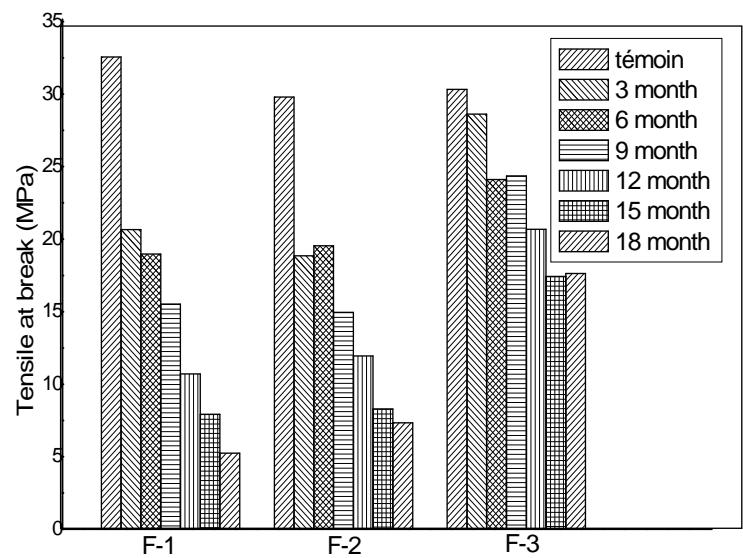

Fig.2 Evolution of Tensile at Break with Control of Ageing

\subsection{FTIR spectroscopic analysis}

Modifications were observed in the spectra of all the aged samples for the three formulations compared to the control (Fig. 3, a, b, c) in two spectral areas: $1654-1850 \mathrm{~cm}-1$ which is the zone of absorption of carbonyls and 3250-3600 cm-1 which is the zone of absorption of hydroxyls and/or hydroperoxyds Similar results were obtained in literature [6-9].

These modifications are related to the appearance of bands due to photoproducts for the three formulations or to the additives for the formulations containing the pro oxidants.

The appearance of a band which is situated at $1714 \mathrm{~cm}-1$ in the case of all the formulations is due to the formation of photoproducts containing the carbonyl group such as esters and ketones.

The formation of a large band in the zone situated between 3200 and $3500 \mathrm{~cm}-1$ in the case of formulation F2 is due to the stretching vibration of the hydroxyl groups (alcohols and hydro peroxides).

The chemical modification of the polymer structure and the presence of oxygenated products (carboxylic acids, alcohols; ketons ...) are related to the photo oxidation of PP under the influence of environment.

During the ageing of PP, instable products like peroxides and hydroperoxids are formed and their decomposition lead to the scission and fragmentation of the polymeric chains with the formation at the extremities of the broken chains of ketons, alcohols and carboxylic acids...These results explains the deterioration of the mechanical properties.

In order to check the level of degradation of the studied formulations, the carbonyl index $(\mathrm{CI})$ was calculated according to the following formula:

\section{$\mathrm{CI}=$ Absorption at $1714 \mathrm{~cm}^{-1} /$ Absorbance at $2925 \mathrm{~cm}^{-1}$}

This index is used to characterize the amplitude of degradation [4]. The absorption of carbonyl can be considered as an index of ageing that allows the global assessment of the progress of the reaction of photo oxidation that leads to a complex mixture of oxidation products such as ketones, acids, esters, peracides, and peresters [10].
According to Figure 4, it can be noted that the formulations containing pro oxidant agents exhibited the highest values of the carbonyl index in comparison to pure PP indicating that the photodagradation of the formulations containing pro oxidant agents is more important. Furthermore, the formulation containing $\mathrm{Ca}$ stearate was photodegraded more quickly than the formulation containing the $\mathrm{Ca} / \mathrm{Zn}$ complex. This fact confirms that $\mathrm{Ca}$ stearate is a more effective pro oxidant agent than the $\mathrm{Ca} / \mathrm{Zn}$ complex.

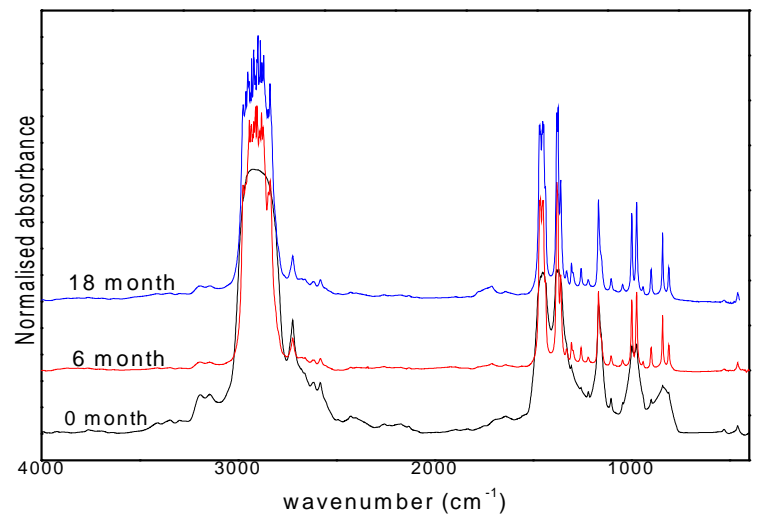

(a)

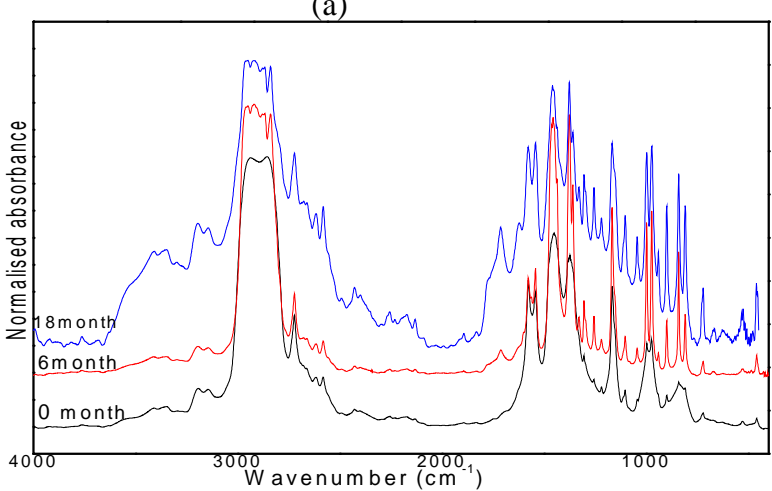

(b)

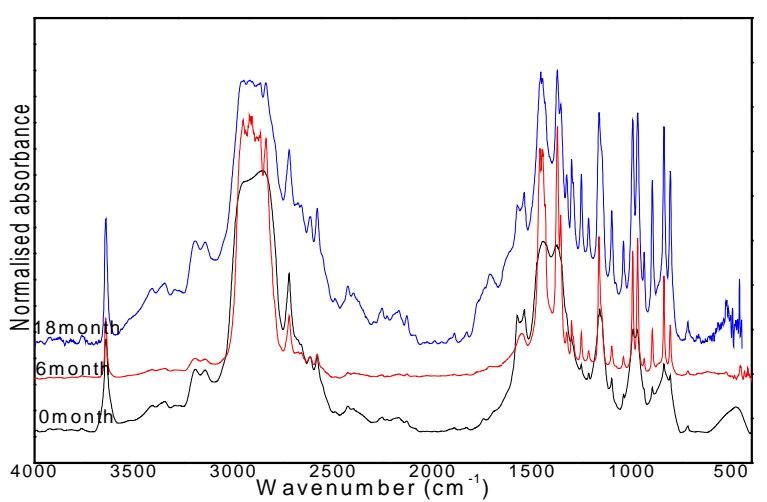

(c)

Fig.3 Evolution of FTIR Spectra of the Three Formulations with Time of Ageing: (a) F1, (b) F2, (c) F3 


\section{References}

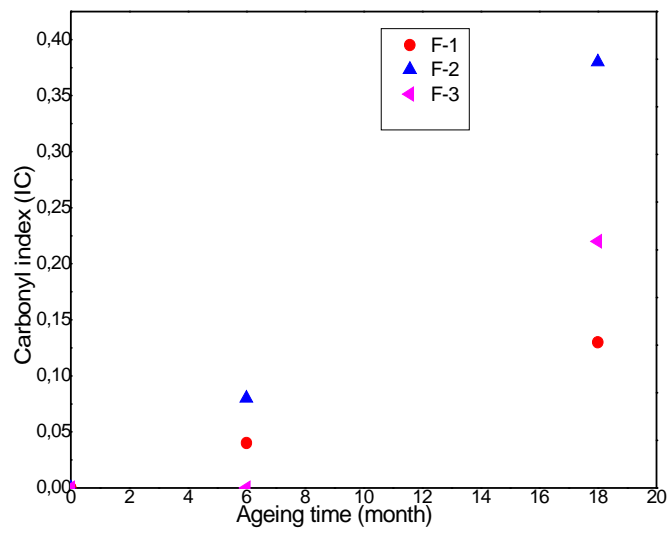

Fig.4 Evolution of the Carbonyl Index with Time of Ageing

\section{Conclusion}

The results showed a decrease in the mechanical properties (tensile and Shore D hardness) since the first months of exposure in the case of the three considered formulations. FTIR spectroscopy showed that the deterioration of mechanical properties is related to the formation of chemical structures due to the chains scissions that occurred during the polymer photo oxidation.

The formulation which contains $\mathrm{Ca}$ stearate exhibited the highest level of degradation in comparison to the formulation containing $\mathrm{Ca} / \mathrm{Zn}$ complex and to PP. Ca stearate is more effective than $\mathrm{Ca} / \mathrm{zn}$ complex as a pro oxidant. Finally, the $\mathrm{Ca}$ stearate can be considered as an accelerator of the degradation of the eventual packaging based on PP.
[1] C. Duval, "Polypropylène", Techniques de l'ingénieur, AM3 320, pp1-16, (2004).

[2] M. Koutny, J. Lemaire, "Biodegradation of polyethylene films with prooxidant additives", Chemosphere, vol.64, pp 1243-1252, (2006).

[3] A. Ammala, S. Bateman, "An overview of degradable and biodegradable polyolefins", Prog. Polym. Sci, vol.36, pp 1015-1049, (2011)

[4] P. K. Roy, P. Surekha, P. Rajagopal, S. N. Chatterjee, V. Choudhary, "Accelerated aging of LDPE films containing cobalt complexes as prooxidants ", Polym. Degrad. \& Stab., vol.91, pp 1791-1799, (2006).

[5] D. S. Rosa, J. M. G. Angelini, J. A. M. Agnelli, L. H. I. Mei, "The use of optical microscopy to follow the degradation of isotactic polypropylene (iPP) subjected to natural and accelerated ageing", Polym.Test, vol. 24, pp 1022-1026, (2004).

[6] S. Aslanzadeh, M. Haghighat Kish"Photodegradation of polypropylene thermal bonded non-woven fabric", Polym.Degr \& Stab,vol. 90, pp461-470, (2005).

[7] J. L. Philippart, C. Sinturel, J. L. Gardette. "Influence of light intensity on the photooxidation of polypropylene". Polym. Degrad. Stab., vol. 58, pp 261-268.(1997).

[8] M. Bertoldo, S. Bronco, C. Cappelli, T. Gragnoli, L. Andreotti. "Combining theory and experiment to study the photooxidation of polyethylene and polypropylene", J. Phys. Chem. B, vol.107, pp 11880-11888, (2003).

[9] M. L. Castejon, P. Tiemblo, J. M. Gomez-Elvira. "Photo-oxidation of thick isotactic polypropylene films: I. Characterization of the heterogeneous degradation kinetics". Polym. Degrad. \& Stab. vol.71, pp 99-111, (2000).

[10] J. Kaloustian, P. Antonetti, A. Berrada, Y. Claire, " Comportement thermique du polypropylène au cours du vieillissement ", J. thermal. Anal, vol.52, pp 327340, (1998). 